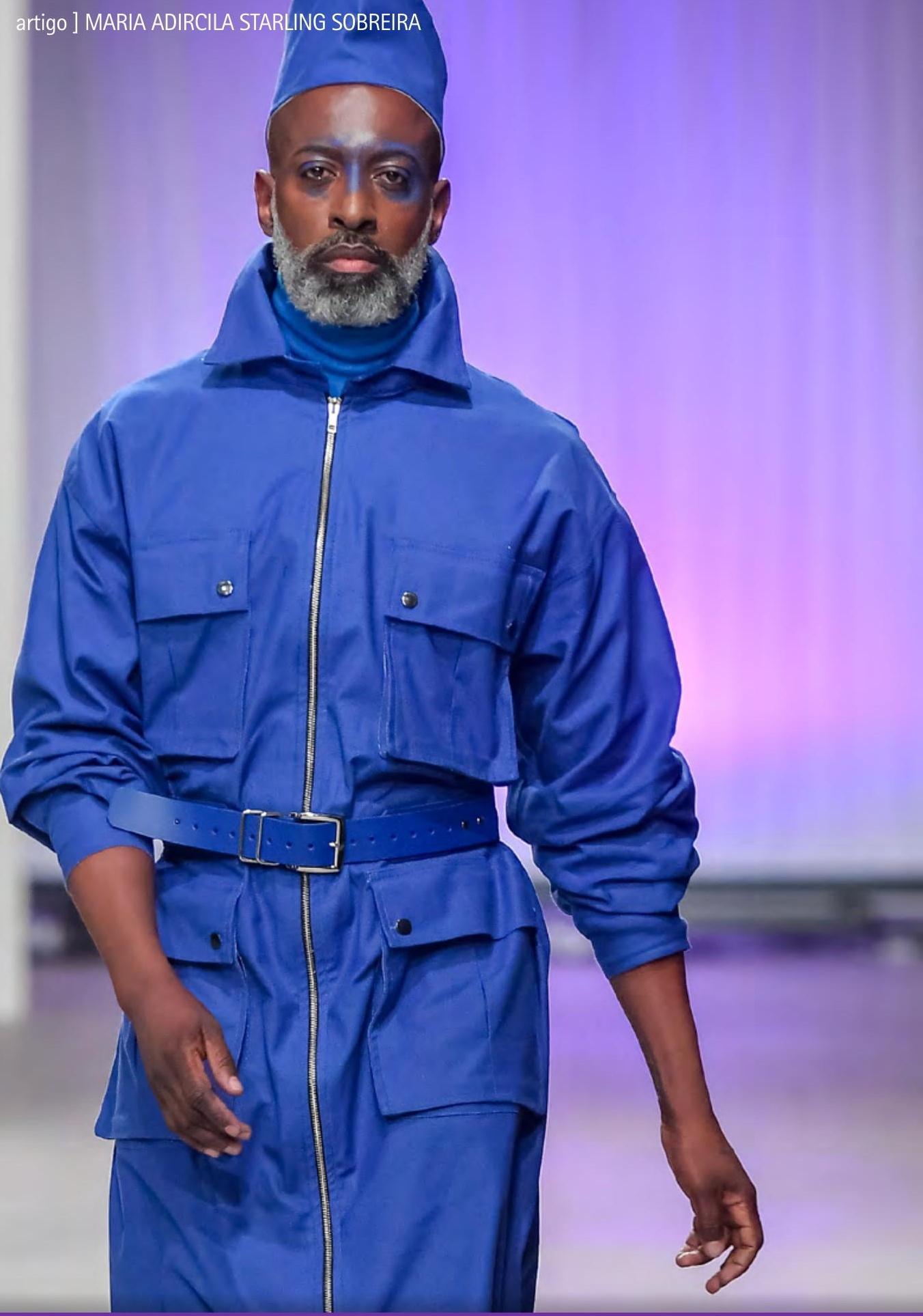

\title{
0 estudo de têxteis no Brasil: uma pesquisa bibliométrica na base de dados Scielo
}

The studies of textiles in Brazil: a bibliometric research in Scielo database 


\author{
[MARIA ADIRCILA STARLING SOBREIRA] \\ Mestre em Engenharia de Materiais. Professora do Centro \\ Universitário UNA \\ E-mail: adircila@gmail.com
}

[resumo] 0 presente artigo tem como objetivo entender e mensurar a pesquisa científica brasileira na área de têxteis disponível na base de dados Scielo. Para tal fim, foi realizada uma pesquisa bibliométrica nos artigos indexados na base referida, de modo a mensurar resultados, seguida de uma pesquisa bibliográfica para interpretá-los. Verificou-se que as áreas em que mais se publicam sobre o assunto são as de química, meio ambiente e gestão. Considerando que o Brasil possui uma das mais completas legislações ambientais, além de ser o quinto maior produtor têxtil do mundo, justifica-se o interesse das pesquisas nestas áreas. No [2I/4 entanto, verificou-se uma lacuna nas áreas de cultura e patrimônio.

\title{
[palavras-chave]
}

\section{têxteis; pesquisa bibliométrica; base} de dados scielo.

[abstract] The present article has the objective to understand and measure the Brazilian scientific research in the area of textiles in Scielo database. In this effort, a bibliometric research to measure results was conducted taking into account the indexed articles from the Scielo database; a bibliographic research was also carried out to interpret the results from the former. It was verified that the areas with the higher number of publications are chemistry, environment and management. Considering that Brazil offers one of the world's most complete environmental legislation, being also the fifth larger textile manufacturer, the interest for publications in these areas is justified. However, there is a gap in areas of culture and heritage.

[keywords] textiles; bibliometric research; Scielo database. 


\section{Introdução}

Têxteis são materiais flexiveis constituídos pelo entrelace de fibras naturais ou artificiais, formando tramas que recebem a denominação comum de tecido. Etimologicamente, a palavra "têxtil" tem origem no latim, derivando do adjetivo textilis (entrelaçado). Desde o surgimento dos primeiros assentamentos humanos até os dias atuais, os materiais têxteis estão presentes em diversas ocasiões cotidianas, tais como vestuário e decoração, além de aplicações técnicas, tais como filtros e ataduras. A origem desse tipo de material remonta à origem das mais antigas civilizações, notadamente a civilização do Antigo Egito, sendo o tecido mais antigo de que se tem notícia datado de 6500 a.C. e encontrado em Israel (LIMA FILHO, 2009).

Atualmente, somente no Brasil, segundo a Associação Brasileira da Indústria Têxtil e de Confecção (Abit), o setor têxtil aparece como o segundo maior empregador, gerando 1,7 milhões de postos de trabalho, e é atualmente o maior empregador de mão de obra feminina. 0 setor abarca mais de 32 mil empresas que produzem 9,4 bilhões de peças, incluindo moda casa. 0 setor têxtil brasileiro tem grande destaque no cenário mundial, principalmente por sua infraestrutura, uma das últimas cadeias têxteis completas do ocidente, produzindo desde as fibras até o produto acabado nas confecções, sendo autossuficiente na produção de algodão. Além da infraestrutura, a Abit aponta como destaque também o profissionalismo, criatividade e tecnologia (ASSOCIAÇÃO..., 2013).

Na sua dimensão acadêmica, o estudo dos materiais têxteis se revela naturalmente interdisciplinar, podendo ser objeto de estudo da engenharia, química, design, antropologia, história e administração. Neste contexto, o objetivo do presente artigo é mensurar como ocorre a pesquisa brasileira sobre o assunto têxtil de uma forma abrangente, dada sua caracteristica interdisciplinar, por meio da pesquisa bibliométrica. Essa forma de pesquisa fornece um parâmetro da produção científica de um determinado local ou determinada área, mensurando-a por meio da análise das palavras-chave, áreas temáticas, periódicos em que mais se publicam e data em que houve mais publicações relativas a têxteis. Para a produção do presente estudo, 0 banco de dados utilizado foi o Scientific Electronic Library Online (Scielo), de grande abrangência no Brasil. Note-se que não será abarcado o design de superficie, um tema que, apesar de dialogar com as disciplinas têxteis, se reveste de suas próprias particularidades técnicas e científicas, constituindo ramo próprio de estudo.

Com o intuito de apresentar uma pesquisa consistente, o presente artigo é dividido em duas partes, além da introdução e conclusão. Na primeira parte discute-se a metodologia empregada na pesquisa - a pesquisa bibliométrica -, enquanto que a segunda parte se ocupa da discussão acerca dos resultados. 


\section{Metodologia - materiais e métodos}

A bibliometria, segundo Araújo (2006, p. 12) é "técnica quantitativa e estatística de medição dos índices de produção e disseminação do conhecimento científico". Seu ponto central, segundo o mesmo autor, é "a utilização de métodos quantitativos na busca por uma avaliação objetiva da produção científica" (ARAÚJO, 2006, p. 12). Silva et al. (2011, p. 111) corroboram Araújo, visto que os autores mostram que a bibliometria estuda e avalia quantitativamente a produção literária científica. No entanto, mostram que a técnica é passivel de críticas, dado o caráter quantitativo e não também qualitativo da abordagem. Os mesmos autores ressaltam que

A literatura cientifica tem revelado que pesquisadores com formação em diversas áreas do conhecimento têm utilizado a bibliometria e a cientometria para realizar "estados da arte" de suas áreas de conhecimento, mapear campos de pesquisa, produzir indicadores de produção científica, analisar padrões de comunicação científica, entre outros (SILVA et al., 2011 p. 111).

0 principal objetivo da presente pesquisa é mapear o estado da arte em relação à produção científica brasileira sobre têxteis no banco de dados bibliográfico Scielo. Para tal, não houve restrição quanto à data de publicação nem à área temática. 0 artigo aborda a produção científica sobre o tema "têxteis" de forma ampla e genérica para englobar os materiais têxteis em toda sua complexidade. Nesse sentido, foram encontradas 63 publicações de 1984 até maio de 2018.

A plataforma Scielo foi escolhida devido a sua acessibilidade e abrangência no Brasil. A Scielo permite acesso a periódicos e publicações gratuitamente, com abrangência na América Latina e Caribe, e na data da pesquisa contava com 1285 periódicos ativos. Tal banco de dados surgiu da associação entre a Fundação de Amparo à Pesquisa de São Paulo (Fapesp) e a base de dados Biblioteca Virtual em Saúde (Bireme). 0 Conselho Nacional de Desenvolvimento Científico e Tecnológico (CNPq) desde 2002 apoia o projeto (PUCCINI et al., 2015, p. 80). A Scielo apresenta uma rigorosa seleção de periódicos, que devem seguir critérios específicos para sua admissão e permanência na base de dados. Dentre os critérios estão o caráter científico, os tipos de documentos, a gestão editorial e o relatório anual de desempenho, dentre outros (SCIELO, 2014).

Foram pesquisados somente artigos cujos autores são brasileiros, ainda que em revista estrangeira, pois o objetivo do artigo é aferir sobre a pesquisa de têxteis realizada por brasileiros. A pesquisa foi realizada entre os dias 24 de abril e 8 de maio de 2018. 
As palavras escolhidas para realizar essa pesquisa foram "têxtil" e "têxteis", visto que, ao se buscar por "tecidos" ou "tecido" nos periódicos brasileiros na área temática de ciências sociais aplicadas, foram encontrados 32 resultados. Porém, destes resultados, apenas uma publicação revelou conteúdo concernente ao estudo dos materiais têxteis, sendo esse resultado incorporado à presente pesquisa. Os demais 31 resultados empregam 0 verbete "tecido" no sentido figurado como, por exemplo, "tecido urbano", "tecido social", "tecido moral". Tais resultados são das mais diversas áreas, como arquitetura, administração, história, por exemplo.

Nesse sentido, a recomendação para autores é que se utilize as palavras "têxteis" ou "têxtil" para referenciar ao objeto "tecido", favorecendo a eficiência na busca de pesquisadores, evitando assim maiores dificuldades para se encontrar a publicação.

\section{Resultados e discussões}

Foram encontradas publicações sobre o tema "têxteis" em quinze periódicos diferentes. De todos, o periódico que mais apresentou publicações sobre têxteis é o Química Nova, com 13 artigos publicados entre os anos de 1998 e 2015. Os assuntos tratados abrangem tingimentos, corantes e tratamento de efluentes têxteis, como se pode observar no quadro abaixo (quadro 1):

\section{Quadro 1: Demonstrativo - títulos dos artigos sobre têxteis publicados} no periódico Química Nova e ano de publicação

\begin{tabular}{|l|c|}
\hline Título dos artigos sobre têxteis publicados no periódico Química Nova & $\begin{array}{c}\text { Ano de } \\
\text { publicação }\end{array}$ \\
\hline $\begin{array}{l}\text { Influência de efluentes têxteis e alimentícios sobre o metabolismo e propriedades } \\
\text { fisicas e químicas do rio Piauitinga (Sergipe) }\end{array}$ & 1998 \\
\hline Corantes têxteis & 2000 \\
\hline Novas tendências no tratamento de efluentes têxteis & 2002 \\
\hline $\begin{array}{l}\text { Avaliação dos tratamentos eletroquímico e fotoeletroquímico na degradação de } \\
\text { corantes têxteis }\end{array}$ & 2006 \\
\hline $\begin{array}{l}\text { Imobilização de ferro (II) em matriz de alginato e sua utilização na degradação de } \\
\text { corantes têxteis por processos Fenton }\end{array}$ & 2008 \\
\hline $\begin{array}{l}\text { Estudo sobre a utilização da lama vermelha para a remoção de corantes em } \\
\text { efluentes têxteis }\end{array}$ & 2008 \\
\hline $\begin{array}{l}\text { Avaliação da biodegradabilidade de efluentes têxteis do beneficiamento } \\
\text { secundário de malhas de poliéster tratados com Reagente de Fenton }\end{array}$ & 2009 \\
\hline Aplicação de ciclodextrinas em processos têxteis & 2010 \\
\hline $\begin{array}{l}\text { Biodegradação de uma mistura de corantes têxteis usando o fungo Ganoderma } \\
\text { SP: um estudo cinético }\end{array}$ & 2011 \\
\hline $\begin{array}{l}\text { Degradação de corantes têxteis e remediação de residuos de tingimento por } \\
\text { processos Fenton, foto-Fenton e eletro-Fenton }\end{array}$ & 2012 \\
\hline $\begin{array}{l}\text { Descoloração de corantes industriais e efluentes têxteis simulados por peroxidase } \\
\text { de nabo (Brassica campestre) }\end{array}$ & 2012 \\
\hline $\begin{array}{l}\text { Processo UV/H202 como pós-tratamento para remoção de cor e polimento final } \\
\text { em efluentes têxteis }\end{array}$ & 2012 \\
\hline $\begin{array}{l}\text { Utilização do compósito nanoestruturado SIO²/TIO2 na fotodegradação de } \\
\text { corantes têxteis com luz solar natural }\end{array}$ & 2015 \\
\hline
\end{tabular}

Fonte: elaborado pela autora com base em Scielo (1984-2018). 
Com 7 artigos publicados sobre materiais têxteis, o segundo periódico em que mais se publicou sobre o assunto foi Engenharia Sanitária e Ambiental (quadro 2). Nota-se a diferença enorme de número de publicações entre o Química Nova e este; observa-se que o primeiro publicou quase que o dobro do segundo sobre o tema "têxteis". Os 7 artigos foram publicados entre 2005 e 2017. Os assuntos tratados abordam tratamento de água da indústria têxtil, com foco principal nos resíduos de tingimento e secundário nos resíduos de lavanderia.

Quadro 2: Demonstrativo - títulos dos artigos sobre têxteis publicados no periódico Engenharia Sanitária e Ambiental e ano de publicação

\begin{tabular}{|l|c|}
\hline $\begin{array}{l}\text { Título dos artigos sobre têxteis publicados no } \\
\text { periódico Engenharia Sanitária e Ambiental }\end{array}$ & $\begin{array}{c}\text { Ano de } \\
\text { publicação }\end{array}$ \\
\hline $\begin{array}{l}\text { Aplicação conjunta de tratamento anaeróbio termofilico por lodo granular } \\
\text { e de mediadores redox na remoção de cor de águas residuárias têxteis }\end{array}$ & 2005 \\
\hline Degradação redutiva de azo-corantes utilizando-se ferro metálico & 2006 \\
\hline Adsorção de índigo carmim em biomassas mortas de aspergillus niger & 2008 \\
\hline $\begin{array}{l}\text { Aplicação de Fenton, foto-Fenton e UV/H202 no tratamento de } \\
\text { efluente têxtil sintético contendo o corante Preto Biozol UC }\end{array}$ & 2011 \\
\hline $\begin{array}{l}\text { Adsorção dos corantes RO16, RR2 e RR141 utilizando } \\
\text { lodo residual da indústria têxtil }\end{array}$ & 2011 \\
\hline $\begin{array}{l}\text { Caracterização de blocos cerâmicos acústicos produzidos } \\
\text { com incorporação de lodo de lavanderia têxtil }\end{array}$ & 2015 \\
\hline $\begin{array}{l}\text { Reator anaeróbio tipo UASB conjugado com processo Fenton para remoção de cor } \\
\text { e demanda química de oxigênio de água residuária sintética de indústria têxtil }\end{array}$ & 2017 \\
\hline
\end{tabular}

Fonte: elaborado pela autora com base em Scielo (1984-2018).

0 períodico Anais do Museu Paulista: história e cultura material apresenta 6 publicações sobre têxteis entre 1994 e 2014 (quadro 3), ocupando o terceiro lugar dos periódicos que mais publicaram sobre têxteis no Brasil. Os assuntos tratados são conservação de têxteis e museologia.

Quadro 3: Demonstrativo - títulos dos artigos sobre têxteis publicados no periódico Anais do Museu Paulista: História e Cultura Material e ano de publicação

\begin{tabular}{|l|c|}
\hline $\begin{array}{l}\text { Título dos artigos encontrados no periódico Anais do } \\
\text { Museu Paulista: História e Cultura Material }\end{array}$ & $\begin{array}{c}\text { Ano de } \\
\text { publicação }\end{array}$ \\
\hline Conservação de têxteis históricos: uma bibliografia introdutória & 1994 \\
\hline $\begin{array}{l}\text { Restauração e conservação: algumas questões para os } \\
\text { conservadores. A perspectiva da conservação de têxteis }\end{array}$ & 1994 \\
\hline A conservação do estandarte da Faculdade de Medicina da Universidade de São Paulo & 2004 \\
\hline $\begin{array}{l}\text { O tecido como assunto: os têxteis e a conservação nas revistas } \\
\text { e catálogos dos museus da USP (1895 - 2000) }\end{array}$ & 2005 \\
\hline Tecidos no museu: argumentos para uma história das práticas curatoriais no Brasil & 2006 \\
\hline $\begin{array}{l}\text { Tecidos decorativos e interiores domésticos oitocentistas na } \\
\text { literatura prescritiva inglesa e norte-americana }\end{array}$ & 2014 \\
\hline
\end{tabular}

Fonte: elaborado pela autora com base em Scielo (1984-2018). 
Em quarto lugar estão os periódicos Journal of the Brazilian Chemical Society, Matéria (Rio de Janeiro) e Polímeros, com 3 artigos publicados em cada um. 0 periódico Journal of the Brazilian Chemical Society publicou sobre têxteis entre 2009 e 2013, e os assuntos abordados foram sobre efluentes têxteis e técnicas de descolorização. Já o periódico Matéria publicou sobre o assunto entre 2013 e 2017. Os artigos tratavam de procedimentos para remoção de corantes e pré-alvejamento. Diferentemente dos dois anteriores, o periódico Polímeros tratou de caracterização térmica e mecânica, mas também tratou de reutilização de soluções de corantes. Este periódico publicou sobre têxteis entre 2005 e 2007. Nos quadros abaixo (quadros 4, 5 e 6) são apresentados os artigos publicados por periódico, bem como 0 ano de publicação.

Quadro 4: Demonstrativo - títulos dos artigos sobre têxteis publicados no periódico Journal of the Brazilian Chemical Societye ano de publicação

\begin{tabular}{|l|c|}
\hline $\begin{array}{l}\text { Título dos artigos sobre têxteis publicados no periódico } \\
\text { Journal of the Brazilian Chemical Society }\end{array}$ & $\begin{array}{c}\text { Ano de } \\
\text { publicação }\end{array}$ \\
\hline $\begin{array}{l}\text { Evolutive follow-up of the photocatalytic degradation of real textile effluents in } \\
\text { TiO2 and TiO2/H2O2 systems and their toxic effects on Lactuca sativa seedlings }\end{array}$ & 2009 \\
\hline Decolorization of textile dyes by cyanobacteria & 2012 \\
\hline $\begin{array}{l}\text { Photoelectrocatalytic degradation of indanthrene blue dye using Ti/ } \\
\text { Ru-based electrodes prepared by a modified Pechini method }\end{array}$ & 2013 \\
\hline
\end{tabular}

Fonte: elaborado pela autora com base em Scielo (1984-2018).

Quadro 5: Demonstrativo - títulos dos artigos sobre têxteis publicados no periódico Polímeros e ano de publicação

\begin{tabular}{|l|c|}
\hline Título dos artigos sobre têxteis publicados no periódico Polimeros & $\begin{array}{c}\text { Ano de } \\
\text { publicação }\end{array}$ \\
\hline $\begin{array}{l}\text { Blenda de náilon-6,6/quitosana como adsorvente de corantes ácidos para } \\
\text { reutilização das soluções de corantes tratadas em tingimentos de poliamida }\end{array}$ & 2008 \\
\hline Caracterização térmica de fios de poliaramida & 2007 \\
\hline $\begin{array}{l}\text { Compósitos de HDPE com resíduos de fibras têxteis. } \\
\text { Parte l: caracterização mecânica }\end{array}$ & 2005 \\
\hline
\end{tabular}

Fonte: elaborado pela autora com base em Scielo (1984-2018).

Quadro 6: Demonstrativo - títulos dos artigos sobre têxteis publicados no periódico Matéria e ano de publicação

\begin{tabular}{|l|c|}
\hline Título dos artigos sobre têxteis publicados no periódico Matéria & $\begin{array}{c}\text { Ano de } \\
\text { publicação }\end{array}$ \\
\hline $\begin{array}{l}\text { Análise da utilização de cerâmica vermelha como adsorvente na remoção do } \\
\text { corante têxtil Direct Blue de uma solução aquosa }\end{array}$ & 2017 \\
\hline $\begin{array}{l}\text { Pre-alvejamento de materiais têxteis com ozônio e avaliação de suas } \\
\text { propriedades de superfície, físicas e tintoriais }\end{array}$ & 2017 \\
\hline $\begin{array}{l}\text { Estudo e caracterização de propriedades da argila esmectita na remoção de } \\
\text { corantes têxteis }\end{array}$ & 2013 \\
\hline
\end{tabular}

Fonte: elaborado pela autora com base em Scielo (1984-2018). 
Em quinto lugar, com apenas 2 publicações sobre têxteis temos os periódicos Brazilian Journal of Microbiology, Gestão \&t Produção, Production e Revista de Administração. Enquanto o primeiro apresentou artigos bem distintos - um sobre higiene de têxteis usados na indústria de alimentos e outro sobre uso de fungos para desgastar fibras têxteis -, os outros 3 abordaram aspectos relativos à atividade empresarial e econômica das indústrias têxteis. São relacionados nos quadros abaixo (quadros 7, 8, 9 e 10) os artigos publicados por periódico e os respectivos anos de publicação.

Quadro 7: Demonstrativo - títulos dos artigos sobre têxteis publicados no periódico Brazilian Journal of Microbiology e ano de publicação

\begin{tabular}{|l|c|}
\hline $\begin{array}{l}\text { Título dos artigos sobre têxteis publicados no } \\
\text { periódico Brazilian Journal of Microbiology }\end{array}$ & $\begin{array}{c}\text { Ano de } \\
\text { publicação }\end{array}$ \\
\hline Monitoramento da higiene de têxteis usados na indústria de alimentos & 2006 \\
\hline $\begin{array}{l}\text { Screening and genetic improvement of pectinolytic } \\
\text { fungi for degumming of textile fiber }\end{array}$ & 2001 \\
\hline
\end{tabular}

Fonte: elaborado pela autora com base em Scielo (1984-2018).

Quadro 8: Demonstrativo - títulos dos artigos sobre têxteis publicados no periódico Gestão \&t Produção e ano de publicação

\begin{tabular}{|l|c|}
\hline Título dos artigos sobre têxteis publicados no periódico Gestão \& Produção & $\begin{array}{c}\text { Ano de } \\
\text { publicação }\end{array}$ \\
\hline $\begin{array}{l}\text { Industrial textile recycling and reuse in Brazil: case study and considerations } \\
\text { concerning the circular economy }\end{array}$ & 2018 \\
\hline $\begin{array}{l}\text { Gerenciamento da transferência internacional de tecnologia: } \\
\text { estudo de caso na indústria têxtil brasileira }\end{array}$ & 2015 \\
\hline
\end{tabular}

Fonte: elaborado pela autora com base em Scielo (1984-2018).

Quadro 9: Demonstrativo - títulos dos artigos sobre têxteis publicados no periódico Production e ano de publicação

\begin{tabular}{|l|c|}
\hline Título dos artigos sobre têxteis publicados no periódico Production & $\begin{array}{c}\text { Ano de } \\
\text { publicação }\end{array}$ \\
\hline $\begin{array}{l}\text { Proposta de seleção e priorização do portfólio de novos produtos em uma } \\
\text { empresa têxtil }\end{array}$ & 2016 \\
\hline $\begin{array}{l}\text { Competitividade, capacitação e aprendizagem tecnológica na indústria de } \\
\text { máquinas têxteis }\end{array}$ & 1997 \\
\hline
\end{tabular}

Fonte: elaborado pela autora com base em Scielo (1984-2018).

Quadro 10: Demonstrativo - títulos dos artigos sobre têxteis publicados no periódico Revista de Administração e ano de publicação

\begin{tabular}{|l|c|}
\hline $\begin{array}{l}\text { Título dos artigos sobre têxteis publicados no periódico } \\
\text { Revista de Administração }\end{array}$ & $\begin{array}{c}\text { Ano de } \\
\text { publicação }\end{array}$ \\
\hline $\begin{array}{l}\text { As relaç̃os entre eco-inovações e o impacto na performance empresarial: uma } \\
\text { pesquisa empirica na indústria têxtil brasileira }\end{array}$ & 2016 \\
\hline Efetividade das estratégias de negócios na indústria têxtil brasileira & 2016 \\
\hline
\end{tabular}

Fonte: elaborado pela autora com base em Scielo (1984-2018). 
Por último, com apenas 1 publicação sobre têxteis, temos os seguintes periódicos: Brazilian Journal of Biology, Educação e Pesquisa, Cadernos de Estudos Africanos, América Latina en la historia económica, Travesía (San Miguel de Tucumán), Cerâmica, Anais da Academia Brasileira de Ciências, Fisioterapia e Pesquisa, Revista Ambiente \&t Água, Revista Brasileira de História, Interações, Nova Economia, Varia Historia, Food Science and Technology, Saúde e Sociedade, Cadernos EBAPE.BR, Economia e Sociedade, Journal of the Brazilian Society of Mechanical Sciences e Bragantia. No quadro abaixo (quadro 11) são relacionados os periódicos, 0 artigo publicado e 0 ano de publicação.

Quadro 11: Demonstrativo - títulos dos artigos sobre têxteis publicados nos periódicos e ano de publicação

\begin{tabular}{|c|c|c|}
\hline Periódico & $\begin{array}{l}\text { Título dos artigos sobre têxteis publicados no } \\
\text { respectivo periódico }\end{array}$ & $\begin{array}{l}\text { Ano de } \\
\text { publicação }\end{array}$ \\
\hline Brazilian Journal of Biology & $\begin{array}{l}\text { Decoloração de águas residuais da indústria têxtil em } \\
\text { fermentação de estado sólido com residuo de Pupunha } \\
\text { (Bactris gasipaes) }\end{array}$ & 2018 \\
\hline Educação e Pesquisa & $\begin{array}{l}\text { Ensino da arte e desenvolvimento da leitura visual: uso da } \\
\text { estamparia têxtil no ensino médio }\end{array}$ & 2018 \\
\hline $\begin{array}{l}\text { Cadernos de Estudos } \\
\text { Africanos }\end{array}$ & $\begin{array}{l}\text { Formas de Resistência Africanas às Autoridades } \\
\text { Portuguesas no Século XVIII: A guerra de Murimuno e a } \\
\text { tecelagem de machira no norte de Moçambique }\end{array}$ & 2017 \\
\hline $\begin{array}{l}\text { América Latina en la historia } \\
\text { económica }\end{array}$ & 0 algodão brasileiro na época da revolução industrial & 2016 \\
\hline $\begin{array}{l}\text { Travesía } \\
\text { (San Miguel de Tucumán) }\end{array}$ & $\begin{array}{l}\text { A indústria na sociedade escravista: um estudo das } \\
\text { fábricas têxteis na região fluminense (1840-1880) }\end{array}$ & 2015 \\
\hline Cerâmica & $\begin{array}{l}\text { Influência do tipo de argila no processo de solidificação/ } \\
\text { estabilização de lodo têxtil }\end{array}$ & 2015 \\
\hline $\begin{array}{l}\text { Anais da Academia Brasileira } \\
\text { de Ciências }\end{array}$ & $\begin{array}{l}\text { Effect of indigo dye effluent on the growth, biomass } \\
\text { production and phenotypic plasticity of Scenedesmus } \\
\text { quadricauda (Chlorococcales) }\end{array}$ & 2013 \\
\hline Fisioterapia e Pesquisa & $\begin{array}{l}\text { Avaliação do risco ergonômico em trabalhadores da } \\
\text { indústria têxtil por dois instrumentos: Quick Exposure } \\
\text { Check e Job Factors Questionnaire }\end{array}$ & 2013 \\
\hline Revista Ambiente \&t Água & $\begin{array}{l}\text { Remoção de corantes têxteis a partir de soluções aquosas } \\
\text { por quitosana modificada com tioacetamida }\end{array}$ & 2013 \\
\hline Revista Brasileira de História & $\begin{array}{l}\text { Não trabalhou porque não quis: greve de trabalhadores } \\
\text { têxteis na Justiça do Trabalho (Bahia, 1948) }\end{array}$ & 2012 \\
\hline Interações & $\begin{array}{l}\text { Artesanato e desenvolvimento local: o caso da } \\
\text { Comunidade Quilombola de Giral Grande, Bahia }\end{array}$ & 2011 \\
\hline Nova Economia & Testando o "Cash-Flow-at-Risk" em empresas têxteis & 2011 \\
\hline Varia Historia & $\begin{array}{l}\text { Os melhores empregados: a inserção e a formação da } \\
\text { mão-de-obra feminina em fábricas têxteis mineiras no } \\
\text { final do século XIX }\end{array}$ & 2011 \\
\hline Food Science and Technology & Extração de corantes de milho & 2009 \\
\hline Saúde e Sociedade & $\begin{array}{l}\text { Comparação da percepção de fadiga e de capacidade para } \\
\text { o trabalho entre trabalhadores têxteis de empresas que } \\
\text { se encontram em diferentes estágios de responsabilidade } \\
\text { social empresarial no estado de São Paulo, Brasil }\end{array}$ & 2008 \\
\hline Cadernos EBAPE.BR & $\begin{array}{l}\text { Modelo de avaliação da estratégia ambiental: estudos no } \\
\text { setor têxtil }\end{array}$ & 2008 \\
\hline Economia e Sociedade & $\begin{array}{l}\text { Abertura comercial, internacionalização e competitividade: } \\
\text { a indústria brasileira de máquinas têxteis após os anos } 1990\end{array}$ & 2007 \\
\hline $\begin{array}{l}\text { Journal of the Brazilian Society } \\
\text { of Mechanical Sciences }\end{array}$ & Investigação para Detecção Automática de Falhas Têxteis & 1999 \\
\hline Bragantia & $\begin{array}{l}\text { Caracterização tecnológica de espécies liberianas para o } \\
\text { estabelecimento de métodos de análise quantitativa de fibras }\end{array}$ & 1993 \\
\hline
\end{tabular}

Fonte: elaborado pela autora com base em Scielo (1984-2018). 
0 gráfico mostrado na figura 1 estabelece um comparativo entre os periódicos e a quantidade de publicações referentes a têxteis.

Figura 1: Gráfico - quantidade de publicações sobre têxteis por periódico

\section{Quantidade de Publicações por periódico}

m Quantidade de Publicações

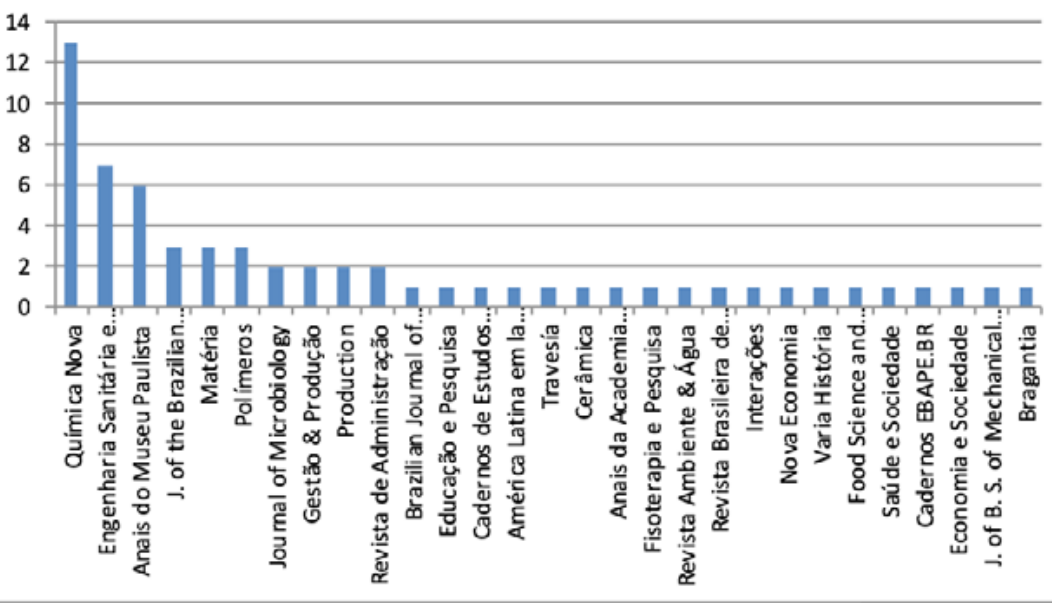

Fonte: elaborado pela autora com base em Scielo (1984-2018).

Outra abordagem que a bibliometria pode trazer à tona é a cronológica. Do ponto de vista cronológico, os anos em que mais se publicaram artigos sobre têxteis foram 2008 e 2011, com seis artigos publicados, seguidos de 2012, 2013 e 2015, com cinco artigos. Com quatro artigos por ano há 2006, 2016 e 2017. Já em relação ao ano de 2018 - note-se que a presente pesquisa foi realizada em maio -, até o momento são 3 artigos publicados. Tais informações podem ser visualizadas na figura 2 .

Figura 2: Gráfico - quantidade de publicações sobre têxteis por ano

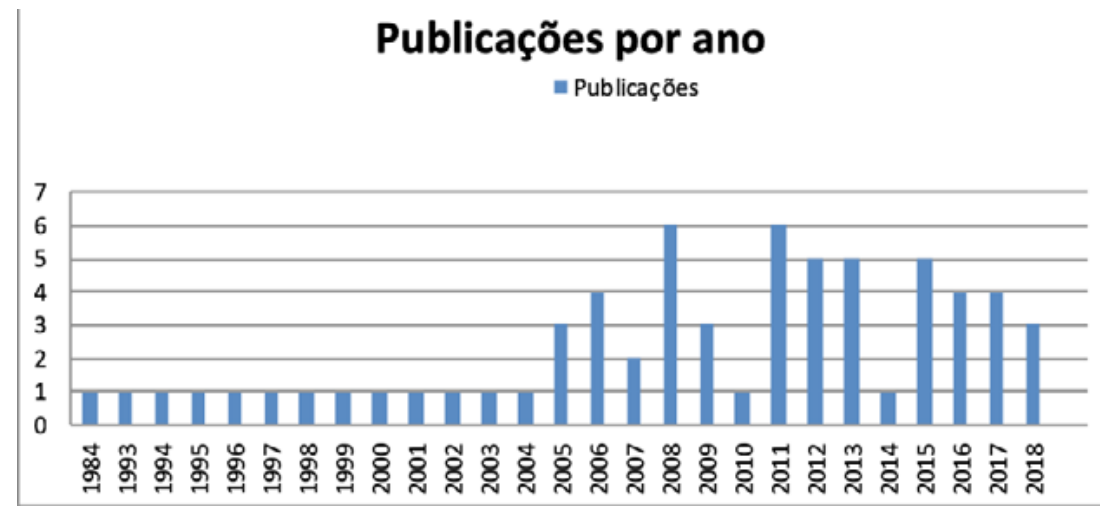

Fonte: elaborado pela autora com base em Scielo (1984-2018).

Em 2008, que, juntamente com 2011, foi o ano em que mais se publicou sobre o tema têxteis, os assuntos abordados nas publicações relacionam-se a condições de trabalho, meio ambiente e processos químicos voltados para efluentes. Nesses artigos, as palavras chaves mais utilizadas foram "fenton" (processo/reagente), "ambiental" (performance, gestão, indicadores, performance e estratégia) e "corantes". 
Já em 2011 houve maior variedade de áreas temáticas: 3 artigos sobre tratamento de efluentes têxteis, 1 sobre artesanato e desenvolvimento local, outro sobre gestão empresarial, além de 1 sobre a inserção da mão de obra feminina na indústria têxtil no século XIX.

Houve 5 publicações de artigos sobre têxteis nos anos de 2012 e 2015. Em 2012, 4 dos 5 artigos publicados vieram de periódicos de química, tratando sobre descoloração e resíduos têxteis. 0 único artigo fora da área de química foi apresentado no periódico Revista Brasileira de História, sobre a greve de trabalhadores têxteis.

Em 2015 encontra-se maior pluralidade de assuntos. Houve artigos nas áreas de história, química, gestão e produção. Desses, 2 artigos abordaram o mesmo tema, tratando de reaproveitamento de resíduo da indústria têxtil na fabricação de cerâmica vermelha. Em um dos periódicos, foi publicada a caracterização, enquanto no outro foi publicada a comparação entre as argilas.

As palavras chave mais utilizadas são "corante(s)" e "tingimento(s)/ dye", utilizadas em 9 publicações, seguida de "indústria têxtil", utilizada em sete. "Têxteis" ou "têxtil" apresentam 6 ocorrências, "adsorção" possui 4 e "reciclagem" 3. Com 2 ocorrências há "reutilização", "algodão", "descoloração" e "conservação". A nuvem de palavras na figura 3 ilustra a frequência das palavras-chave, mostrando em escala maior as palavras com mais ocorrências e progressivamente menores as que possuem menos ocorrências.

Figura 3: Palavras-chave mais utilizadas nos artigos com o tema "têxteis" encontrados na base de dados Scielo

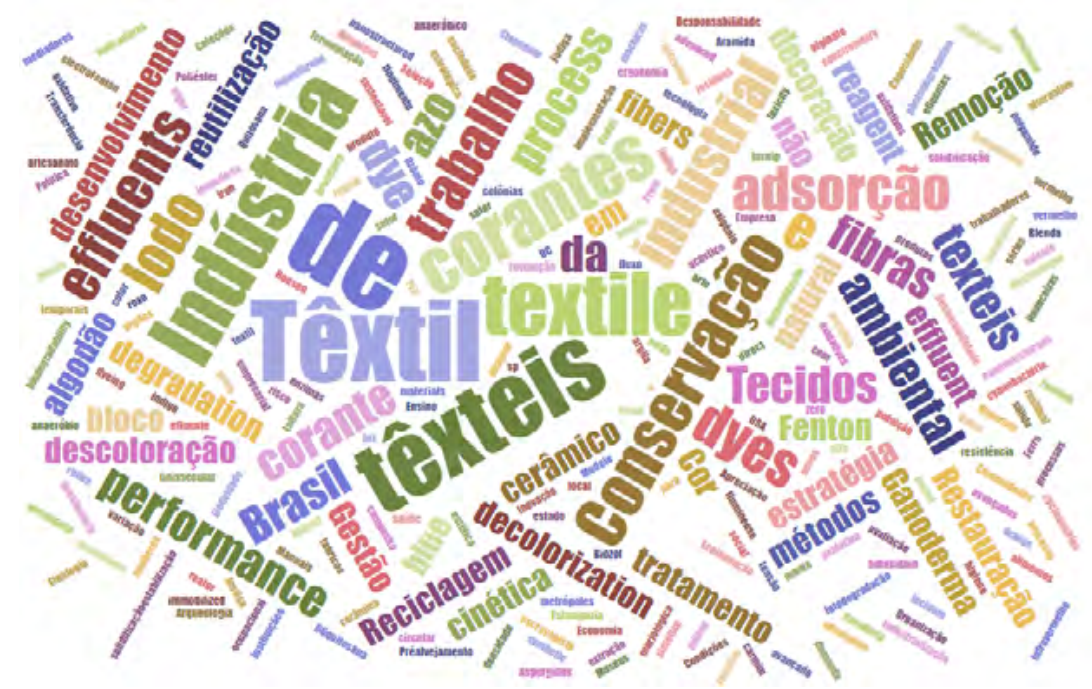

Fonte: elaborada pela autora com base em Scielo (1984-2018). 
As primeiras publicações relacionadas a têxtil e cultura foram publicadas em 1994 no periódico Anais do Museu Paulista: História e Cultura Material e tratam de restauração e conservação de têxteis. Foram publicados na mesma edição uma resenha e um artigo sobre bibliografia introdutória. Somente dez anos depois o mesmo periódico publicou outro artigo sobre têxteis, também sobre conservação. Em 2005 houve outra publicação no mesmo periódico e sobre o mesmo assunto. Já em 2006, publicaram um artigo sobre museologia e têxteis. No ano de 2011, o periódico Varia Historia publica um artigo sobre o ponto de vista histórico da inserção de mão de obra feminina nas fábricas têxteis. No mesmo ano, o periódico Interações publica sobre desenvolvimento local através de artesanato com retalhos têxteis feito por uma comunidade quilombola. Em 2014, os Anais do Museu Paulista: História e Cultura Material publicam sobre tecidos decorativos oitocentistas.

Nota-se uma grande lacuna no que tange aos têxteis enquanto cultura, museologia, história e patrimônio. Foram encontrados 63 artigos pelo banco de dados Scielo, dos quais apenas 8 são sobre tais assuntos. Os assuntos mais discutidos são na área ambiental, abordando resíduos e tratamentos de efluentes da indústria têxtil. Há também discussões sobre gestão empresarial na área têxtil.

A indústria têxtil é uma das mais poluentes e "das que mais se envolve com problemas ambientais relacionados aos efluentes e resíduos sólidos perigosos" (GRAVELET et al., 1997, p. 305). Isso acontece principalmente nas fases de beneficiamento têxtil, em que se descolore e/ou se tinge 0 tecido, utilizando grande quantidade de água e produtos químicos, tais como corantes, metais pesados, ácidos, soda cáustica e carbonato de sódio (ALCÂNTARA; DALTIN, 1996, p. 325; ARAÚJO; CASTRO, 1984, p. 695-828). Logo, a indústria têxtil possui um potencial contaminante considerado médio, segundo as autoras Berlim (2009, p. 24) e Santos (1997, p. 6). Esses dados justificam a preocupação acadêmica com os impactos ambientais causados pela indústria têxtil. 0 Brasil possui uma das mais completas e avançadas leis ambientais do mundo, segundo o próprio governo (BRASIL, 2010), o que indica a constante preocupação ambiental e em se tratar efluentes e dejetos da indústria têxtil. São tomados como marcos na criação da legislação ambiental no Brasil o Código de Florestas, o Código de Águas e o Código de Minas, de 1934, no período Vargas. Ambos tinham como objetivo legislar sobre o acesso e uso dos recursos naturais, visto os processos de urbanização e industrialização pelos quais passava a sociedade brasileira. A partir da década de 1970, nota-se influências oriundas do debate ambiental, não apenas motivações desenvolvimentistas (SILVA; LIMA, 2013 p. 239). A partir de 1973, há a formação de agências ambientais pertencentes ao sistema ambiental, tal como mostrado no quadro 12: 
Quadro 12: Ano de criação das agências ambientais brasileiras

\begin{tabular}{|l|c|}
\hline Agências ambientais & $\begin{array}{c}\text { Ano de } \\
\text { criação }\end{array}$ \\
\hline Secretaria Especial de Meio Ambiente (Sema) & 1973 \\
\hline Instituto Brasileiro do Meio Ambiente e dos Recursos Naturais Renováveis (lbama) & 1989 \\
\hline Ministério do Meio Ambiente & 1993 \\
\hline Agência Nacional de Águas (Ana) & 2001 \\
\hline Instituto Chico Mendes de Conservação da Biodiversidade (ICMBio) & 2007 \\
\hline
\end{tabular}

Fonte: elaborado pela autora com base em Silva; Lima (2013).

Além da criação das agências, houve a implantação da Política Nacional de Meio Ambiente (PNMA), em 1981, um importante marco histórico no que tange à questão ambiental no Brasil, uma vez que institucionalizou o Sistema Nacional do Meio Ambiente (Sisnama) e o Licenciamento Ambiental (IMPERIANO, 2007), formalizando ainda mais o tratamento as questões ambientais.

Deve-se considerar também que a indústria têxtil representa um dos setores mais tradicionais do Brasil. Em 1920, essa atividade fabril empregava $41 \%$ da mão de obra da indústria de transformação. Hoje, os números continuam expressivos (URBAN et al., 1995 p. 12-14). Os setores têxtil e de confecção nacionais apresentaram faturamento de 45 bilhões de dólares em 2017, com produção média de têxteis (excluindo confecção) de 1,7 milhões de toneladas (ASSOCIAÇÃO..., 2017). Esse resultado eleva o Brasil à posição de quinto maior produtor têxtil do mundo. Além disso, o referido setor se revela o segundo maior empregador da indústria de transformação, o maior empregador de mão de obra feminina e o maior gerador do primeiro emprego no país. Em 2017, contava com 1,479 milhão de empregados diretos, representando 16,7\% dos empregos (ASSOCIAÇÃO..., 2017). Além do mais, há a constante ameaça dos tecidos chineses, que invadem o país. Segundo a mesma associação, em sua agenda de prioridades 2015-2018:

0 mundo têxtil é mais de 50\% asiático, com destaque para a China. Os asiáticos lideram todas as estatísticas do setor: maiores exportadores, maiores produtores, maiores empregadores, maiores produtores de algodão, maiores investimentos, maiores empresas (ASSOCIAÇÃO..., 2014, p. 8).

Todos esses dados justificam o interesse acadêmico das áreas de gestão.

No entanto, têxteis também são parte fundamental da cultura, e apenas 6 artigos indexados no Scielo tratam disso, mostrando uma 
grande lacuna. Ao se pesquisar sobre o porquê desse desinteresse, Neira $(2015$, p. 5), citando outras fontes, diz que:

[...] o patrimônio têxtil brasileiro não recebeu a merecida atenção e nem foi devidamente estudado ao longo do tempo por duas razões principais. A primeira se deve ao fato que enquanto artefato seu valor econômico é baixo se comparado a outras tipologias. Em segundo lugar, mas não menos relevante, na maioria das vezes objetos constituídos de têxteis originam-se do universo feminino ou com ele se relacionam fazendo que em termos simbólicos tenham sido considerados pouco relevantes ao longo da história (PAULA, 2004; ANDRADE, 2006), descaso esse notado não somente no Brasil, mas alertado também por pesquisadores europeus e norte-americanos.

Além disso, a mesma autora cita ainda motivos de ordem prática, tais como a efemeridade do material, sua sazonalidade e diversidade, que dificultam o estudo têxtil.

Neira (2015) afirma que têxteis vão além da indumentária, e abrangem também têxteis domésticos, como tapeçaria e cobertura de estofados. Os têxteis enquanto patrimônio são divididos em três grandes categorias: eclesiásticos, militares e civis.

A autora ainda reafirma a importância dos têxteis como documentos históricos, e mostra que, no Brasil, somente na década de 1980 foram iniciados esforços de conservação desse tipo de matéria-prima.

Um outro ponto que deve ser considerado são os critérios rigorosos para seleção e permanência de periódicos na base de dados Scielo. Tais critérios favorecem pesquisas prioritariamente quantitativas em detrimento das pesquisas qualitativas, o que privilegia as ciências exatas, como química, em detrimento das ciências culturais, que abarcam cultura e patrimônio. Por esse motivo, periódicos importantes da produção acadêmica brasileira no assunto têxteis não são indexados na base de dados Scielo, como a revista dObra[s], classificada pela Coordenação de Aperfeiçoamento de Pessoal de Nivel Superior (Capes) como Qualis B2 em Estudos em Design, com classificação A2 para o quadriênio 2013-2016. É importante observar que, por esses motivos, a base de dados Scielo, apesar de toda sua relevância para a comunidade acadêmica brasileira, não reflete exatamente a produção brasileira sobre têxteis. Artigos relevantes, como "A camisola do dia: patrimônio têxtil da cultura material nupcial (Rio Grande do Sul, do início a meados do século XX)" e "Discursos distintivos a partir da cultura material têxtil no Brasil (1847-1910)", apresentados pelo periódico Estudos 
Históricos, classificado como A1, não foram indexados pela base de dados Scielo, o que demonstra que o assunto não é quantitativamente significante nesta base e há lacunas importantes a serem consideradas.

\section{Conclusão}

Por meio da análise bibliométrica utilizando o banco de dados Scielo, foi possivel mapear a produção intelectual já desenvolvida sobre têxtil. Essa análise evidenciou o perfil das pesquisas feitas por pesquisadores brasileiros, incluindo publicações em revistas estrangeiras, sobre o tema. A área em que mais se pesquisa sobre têxteis é inegavelmente a química, seguida da área de gestão e de cultura. Foi evidenciada uma grande lacuna na área de cultura, conservação e patrimônio, o que pode representar uma oportunidade de pesquisa na área, uma vez que ainda há um campo fértil para estudo ainda não explorado.

Essa pesquisa apresenta limitações, pois utilizou somente um banco de dados, o Scielo, e se restringiu a publicações com autores brasileiros, mesmo que em periódicos publicados em outros paises. Por esses motivos, foram analisados somente 64 artigos de 1984 a maio de 2018, o que não permite uma generalização sobre o tema. 0 banco de dados Scielo possui limitações de indexação. Alguns periódicos de relevância nacional não têm suas publicações encontradas no Scielo, visto que algumas áreas de conhecimento apresentam outras fontes de busca, como por exemplo, o Google Acadêmico.

Como sugestão para pesquisas futuras, recomenda-se ampliar a busca para mais bancos de dados e, posteriormente, comparar com números referentes a publicações internacionais. Outra sugestão é comparar a localização geográfica das maiores indústrias têxteis brasileiras e as regiões dos centros de pesquisa que mais publicam sobre 0 assunto.

Recebido: 29-09-2018

Aprovado: 26-10-2018 


\section{REFERÊNCIAS}

ALCÂNTARA, M.; DALTIN, D. A química do processamento têxtil. Química Nova On-Line, v. 19, n. 3 , maio/jun. 1996. Disponivel em: http://quimicanova.sbq.org.br/imagebank/pdf/Nol19No3_320_v19_ n3_17.pdf. Acesso em: 16 maio 2018.

ARAÚJO, M.; CASTRO, E. M. Manual de Engenharia Têxtil. v. 2. Lisboa: Fundação Calouste Gulbenkian, 1984.

ARAUJO, C. A. Bibliometria: evolução histórica e questões atuais. Em Questão [en linea], v. 12, n. 1, p. 11-32, jan./jun. 2006. Disponivel em: http://www.redalyc.org/articulo.oa?id=465645954002. Acesso em: 15 maio 2018.

ASSOCIAÇÃO BRASILEIRA DA INDÚSTRIA TÊXTIL E DE CONFECÇÃO. Indústria têxtil e confecção brasileira. Brasilia, jun. 2013. Disponivel em: http://www.abit.org.br/conteudo/links/publicacoes/ cartilha_rtcc.pdf. Acesso em: 13 jul. 2018.

ASSOCIAÇÃO BRASILEIRA DA INDÚSTRIA TÊXTIL E DE CONFECÇÃO. Agenda de Prioridades Têxtil e Confecção 2015 a 2018. São Paulo, 2014. Disponivel em: http://www.abit.org.br/conteudo/links/ publicacoes/agenda_site.pdf. Acesso em: 20 maio 2018.

ASSOCIAÇÃO BRASILEIRA DA INDÚSTRIA TÊXTIL E DE CONFECÇÃO. Perfil do Setor. 2017. Disponivel em: http://www.abit.org.br/cont/perfil-do-setor. Acesso em: 25 maio 2018.

BERLIM, L G. Moda, a possibilidade da leveza sustentável: tendências, surgimento de mercados justos e criadores responsáveis. 2009. Dissertação (Mestrado em Ciência Ambiental) - Universidade Federal Fluminense, Niterói, 2009. Disponível em: https://drive.google.com/file/ d/0B67qzHzhRv70dEUzWFyRIdjMFk/view. Acesso em: 28 maio 2018.

BRASIL Legislação ambiental no Brasil é uma das mais completas do mundo. Brasilia, 20 out. 2010 Disponivel em: http://www.brasil.gov.br/meio-ambiente/2010/10/legislacao. Acesso em: 20 maio 2018.

GRAVELET, L R.; BARCLAY, S. J.; CARLIELL, C. M. e BUCKLEY, C. A. Management of Water Resources in South Africa with Respect to the Textile industry. Water Science and Technology, v. 36, n. 2-3, p. 303-310, 1997.

IMPERIANO, B O. Direito e gestão ambiental: o que as empresas devem saber. João Pessoa: Sal da Terra, 2007.

LIMA FILHO, A. V. de. Organização política, jurídica e social do Egito no Antigo Império. Revista da Faculdade de Direito da Universidade de São Paulo, v. 104, 2009. Disponivel em: https://www. revistas.usp.br/rfdusp/article/download/67849/70457/. Acesso em: 12 jul. 2018.

NEIRA, L G. Têxteis como patrimônio cultural. Cultura histórica e patrimônio, v. 3, n. 1, p. 5-23, 2015. Disponivel em: https://publicacoes.unifal-mg.edu.br/revistas/index.php/cultura_historica_ patrimonio/article/view/01_art_v3n1_neira/262. Acesso em: 20 maio 2018.

PUCCINI, L R. S. et al. Comparativo entre as bases de dados PubMed, SciELO e Google Acadêmico com o foco na temática Educação Médica. Cadernos UniFOA, Volta Redonda, n. 28, p. 75-82, ago. 2015.

SANTOS, S. Impacto ambiental causado pela indústria têxtil. Universidade Federal de Santa Catarina, 1997. Disponivel em: http://www.abepro.org.br/biblioteca/enegep1997_t6410.pdf. Acesso em: 10 jun. de 2018.

SCIELO. Critérios, política e procedimentos para a admissão e a permanência de periódicos científicos na Coleção SciELO Brasil. São Paulo: Fapesp, Capes, CNPq, Bireme, FapUnifesp, 2014. Disponivel em: http://www.scielo.br/avaliacao/20141003NovosCriterios_SciELO_Brasil.pdf. Acesso em: 24 out. 2018.

SCIELO. São Paulo: Fapesp, Capes, CNPq, Bireme, FapUnifesp, 1984-2018. Disponivel em: http:// www.scielo.org/php/index.php. Acesso em 9 jun. de 2018.

SILVA, D. F.; LIMA, G. F. da C. Empresas e meio ambiente: Contribuições da legislação ambiental. Revista Internacional Interdisciplinar INTERthesis, v. 10, n. 2, p. 334-359, 2013. Disponivel em: https://periodicos. ufsc.br/index.php/interthesis/article/view/1807-1384.2013v10n2p334. Acesso em: 9 jun. 2018.

SILVA, M. R. et al. Análise bibliométrica e cientométrica: desafios para especialistas que atuam no campo. CID: R. Ci. Inf. e Doc, Ribeirão Preto, v. 2, n. 1, p. 110-129, jan.jjun. 2011. Disponivel em: http://www.revistas.usp.br/incid/article/view/42337. Acesso em: 4 set. 2018.

URBAN, M. L de P. et al. Desenvolvimento da produção de têxteis de algodão no Brasil. Informações Econômicas, v. 25, n. 12, dez. 1995. Disponivel em: ftp://ftp.sp.gov.br/ftpiea/tec1-1295.pdf. Acesso em: 30 maio 2018. 


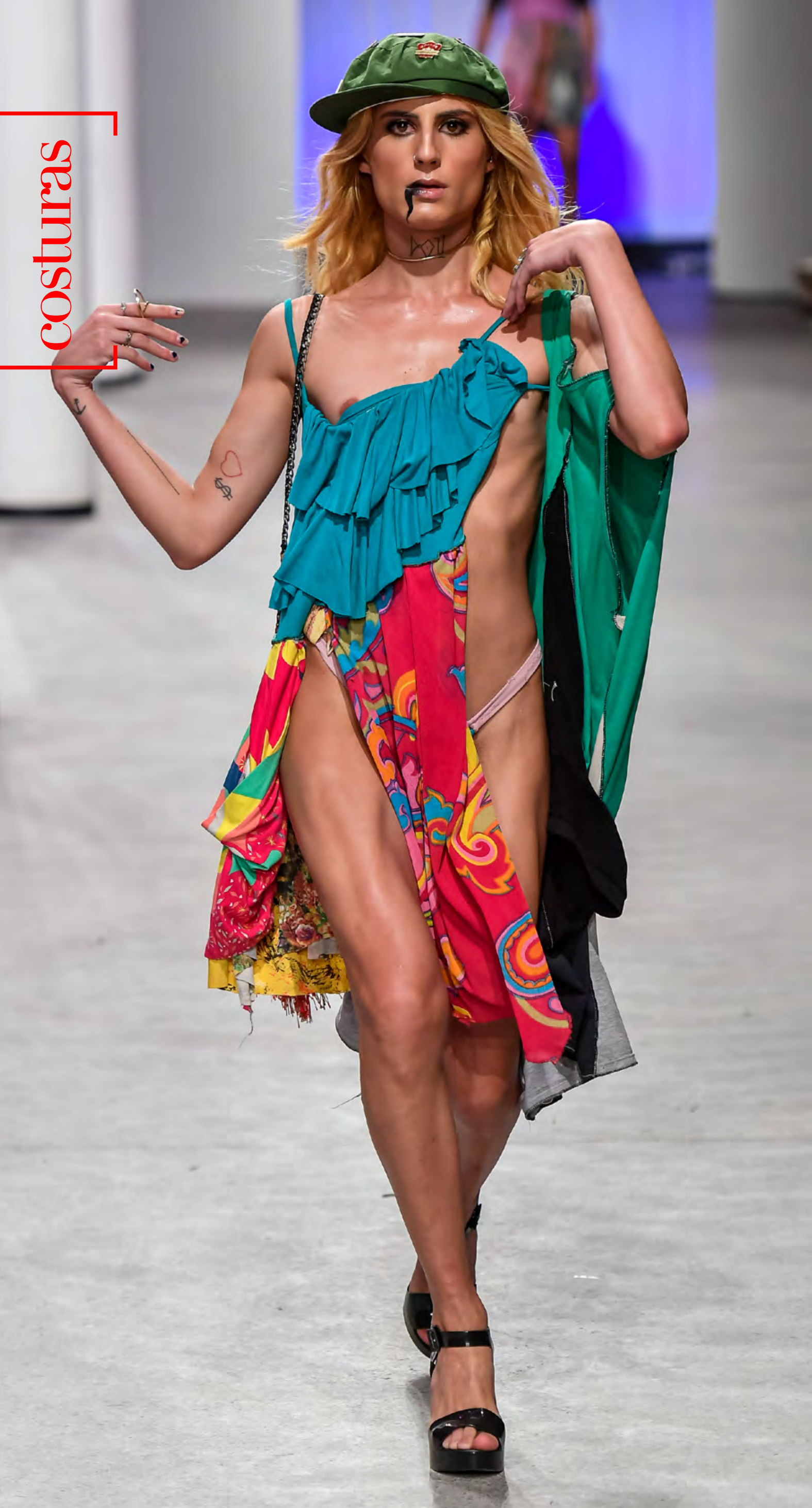

